\title{
Perspectivas do uso de células-tronco na cirurgia plástica
}

\author{
Perspectives on the use of stem cells in plastic surgery \\ Perspectivas sobre el uso de células madre en cirugía plástica
}

Amanda Silva de Moraes ${ }^{1 *}$, Ana Luara Barcelos Silva ${ }^{2}$, Beatriz Palácio Andrade ${ }^{3}$, Caroline Curcio Dobelin ${ }^{4}$, Estefane Ribeiro Melo ${ }^{5}$, Gabriela Oliveira Silva ${ }^{6}$, Luísa Correia de Aguiar ${ }^{1}$, Maria Vitória Almeida Moreira ${ }^{7}$, Melissa Macêdo Peixoto Nascimento ${ }^{8}$, Wagner Pablo Corrêa ${ }^{9}$.

\section{RESUMO}

Objetivo: Revisar a literatura atualizando os principais usos e as perspectivas futuras de células tronco em cirurgia plástica e sua aplicação na restauração estética e funcional de tecidos com defeitos congênitos ou adquiridos. Revisão bibliográfica: Células-tronco, em especial as mesenquimais, são apontadas na literatura com significativo potencial promissor na aplicação da terapia celular, principalmente devido a sua variedade celular e elevada capacidade de autorrenovação e diferenciação, com fonte de obtenção expressiva em tecido subcutâneo e pele, através de procedimentos cirúrgicos. Este material biológico, retirado em procedimentos estéticos em cirurgia plástica, pode ser aproveitado e é eficiente para reconstrução tecidual, como no tratamento de cicatrizes, feridas e fístulas crônicas e reconstruções mamárias. Barreiras a serem enfrentadas envolvem o cuidado com comorbidades do paciente, segurança do material biológico e custos do preparo. Apesar disso, os estudos vêm mostrando perspectivas promissoras de crescente desenvolvimento destas aplicações, dado que a terapia com células-tronco conseguiu promover melhores resultados em questão de estética. Considerações finais: Visando a importância e avanço da medicina regenerativa em cirurgia plástica com o uso de células-tronco, torna-se imprescindível o entendimento da sua prática e utilização terapêutica.

Palavras-chave: Células-tronco, Cirurgia plástica, Terapia celular.

\begin{abstract}
Objective: Review the literature, updating the main uses and future perspectives of stem cells in plastic surgery and their application in aesthetic and functional restoration of tissues with congenital or acquired defects. Bibliographic review: Stem cells, especially mesenchymal cells, are pointed out in the literature with significant promising potential in the application of cell therapy, mainly due to their cell variety and high capacity for self-renewal and differentiation, with a significant source of achievement subcutaneous tissue and skin, through surgical procedures. This biological material, removed in aesthetic procedures in plastic surgery, can be used and is efficient for tissue reconstruction, as in the treatment of scars, wounds and chronic fistulas and breast reconstructions. Barriers to be faced involve care for patient comorbidities, safety of biological material and costs of preparation. Despite this, studies have shown promising prospects for the growing development of these applications, given that stem cell therapy has managed to promote better results in terms of aesthetics. Final considerations: Considering the importance and advancement of regenerative medicine in plastic surgery with the use of stem cells, it is essential to understand its practice and therapeutic use.
\end{abstract}

Keywords: Stem cells, Plastic surgery, Cell therapy.

\footnotetext{
${ }^{1}$ Centro Universitário do Planalto Central (UNICEPLAC), Brasília - DF.

*E-mail: amandaamoraeess@gmail.com

2 União das Faculdades dos Grandes Lagos (UNILAGO), São José do Rio Preto - SP.

3 Universidade Potiguar (UNP), Natal - RN.

${ }^{4}$ Universidad Privada Del Este, Franco, Paraguai.

5 Universidade de Pernambuco (UPE), Garanhuns - PE.

${ }^{6}$ Universidade de Taubaté (UNITAU), Taubaté - SP.

7 Universidade Nilton Lins, Manaus - AM.

8 Universidade de Fortaleza (UNIFOR), Fortaleza - CE.

9 Faculdade de Medicina do Vale do Aço (UNIVAÇO), Ipatinga - MG.
} 


\section{RESUMEN}

Objetivo: Revisar la literatura, actualizando los principales usos y perspectivas de futuro de las células madre en cirugía plástica y su aplicación en la restauración estética y funcional de tejidos con defectos congénitos o adquiridos. Revisión bibliográfica: Las células madre, especialmente las células mesenquimales, se señalan en la literatura con un importante potencial en la aplicación de la terapia celular, principalmente por su variedad celular y alta capacidad de autorrenovación y diferenciación, con una importante fuente de obtención tejido subcutáneo, mediante procedimientos quirúrgicos. Este material biológico, extraído en procedimientos estéticos en cirugía plástica, puede utilizarse y es eficaz para la reconstrucción de tejidos, como en el tratamiento de cicatrices, heridas y fístulas crónicas y reconstrucciones mamarias. Las barreras a enfrentar incluyen el cuidado de las comorbilidades del paciente, seguridad del material biológico y costos de preparación. A pesar de esto, los estudios han mostrado perspectivas prometedoras para el desarrollo creciente de estas aplicaciones, dado que la terapia con células madre ha logrado promover mejores resultados en términos de estética. Consideraciones finales: Considerando la importancia y el avance de la medicina regenerativa en la cirugía plástica con el uso de células madre, es fundamental comprender su práctica y uso terapéutico.

Palabras clave: Células madre, Cirugía plástica, Terapia celular.

\section{INTRODUÇÃO}

Células tronco são caracterizadas como indiferenciadas e com capacidade de renovação, plasticidade, alta proliferação e migração ativa para tecidos e órgãos danificados e, por isso, têm grande potencial para regeneração. Apesar do seu elevado potencial e eficiência, as células tronco embrionárias estão envolvidas em processos éticos e religiosos que dificultam seu uso mundialmente. Diante disso, os estudos recentes são focados em células tronco somáticas que podem passar por um processo de reprogramação induzida (induced pluripotent stem cells - IPSC) para se transformar nos diversos tipos celulares. Essas células reprogramadas não ocasionam problemas éticos, são paciente-específicas e não imunogênicas, sendo mais facilmente toleradas pelo organismo (BOHÁČ M, et al., 2016).

As células tronco adultas ou somáticas podem ser desenvolvidas a partir de células especializadas do ectoderma (células epidérmicas da pele, neurônios e células pigmentadas), mesoderma (células do músculo cardíaco, músculo estriado, músculo liso, tubulares do rim, sanguíneas, tecido adiposo) e endoderma (células pancreáticas, da tireoide, alveolares) e células germinativas (óvulo e espermatozóide). A partir desse contexto, células do tecido adiposo e da pele se tornaram fontes de obtenção e diferenciação de células tronco, abrindo novas perspectivas de tratamento em diversas especialidades (GOMES RS, 2011).

Pelo fato das células serem multipotentes, estão restritas à linhagem celular na qual residem. Mas, independentemente disso, as células-tronco adultas são células altamente úteis na medicina regenerativa, devido à sua facilidade de isolamento, diferenciação e potencial para transplante autólogo. O que faz com que elas sejam candidatas favoráveis para o uso clínico (SALIBIAN AA, et al., 2013).

Em razão de suas características, as células tronco adultas são muito atrativas para o ramo da cirurgia plástica estética e reconstrutiva, uma vez que tem como intuito restaurar a forma e a função de inúmeros defeitos congênitos e adquiridos. Essas técnicas são muito úteis na regeneração de feridas crônicas, promoção de angiogênese, minimização de inflamação, cicatrização de fístulas e reconstrução de mama, ossos, tendões e nervos periféricos (NADERI N, et al., 2016).

A maior vantagem da terapia com células-tronco é evitar procedimentos cirúrgicos que podem ser prejudiciais ao paciente. A terapia com células-tronco é capaz de fornecer um tratamento eficaz para o tratamento de defeitos ósseos e de tecidos moles, sendo capaz de promover também a cicatrização de feridas complicadas por isquemia, como diabéticas. A terapia com células tronco acaba se tornando extremamente atrativa em tratamentos de rejuvenescimento da pele e melhora de cicatrizes (EUN SC, 2014)

Nesse sentido, o presente estudo tem como objetivo realizar uma revisão de literatura com análise dos principais usos das células tronco no ramo da cirurgia plástica e as perspectivas futuras da sua aplicação na restauração estética e funcional de tecidos com defeitos congênitos ou adquiridos. 


\section{REVISÃO BIBLIOGRÁFICA}

Células-tronco, por definição, são células indiferenciadas que possuem a capacidade de se proliferar, produzir células funcionais diferenciadas e se regenerar após uma lesão (LOEFFLER M, et al.,1997). Ademais, ainda como característica, são capazes de autorrenovação prolongada através de consecutivas segmentações mitóticas do tipo assimétrica e suscetível de criar pelo menos uma variedade celular em fase mais avançada de diferenciação (MORRISSON SJ, et al., 1997).

As células-tronco podem ser classificadas de diferentes formas, como de acordo com seu tecido de origem e capacidade de diferenciação celular. Quanto à classificação de acordo com o potencial de diferenciação, é possível classificar em três tipos: totipotentes, pluripotentes e multipotentes (ROBEY PG, 2000).

As células-tronco totipotentes são capazes de originar um organismo totalmente funcional e, também são capazes de dar origem a qualquer tipo celular do corpo, inclusive a todo o sistema nervoso central e periférico (GAGE FG, 2000). Já as células pluripotentes são capazes de originar qualquer tipo de tecido, porém não originam um organismo completo, já que não são capazes de gerar tecidos embrionários (ROBEY PG, 2000).

Alguns dos fatores essenciais para o crescimento de células tronco incluem: os componentes celulares, fatores secretados, como quimiocinas e sinalizadores moleculares, células inflamatórias, matriz extracelular e metabolismo (AGRAWAL NA, et al., 2019).

As células-tronco multipotentes são mais diferenciadas, estão presentes no indivíduo adulto e têm a capacidade de originar um restrito número de variedades teciduais. Estas são caracterizadas de acordo com o órgão do qual provém e podem criar apenas células deste órgão, possibilitando a regeneração tecidual local (GAGE FG, 2000). Essas células podem ser extraídas de diferentes tipos de tecidos como medula óssea, cordão umbilical, encéfalo, epitélio, polpa dentária e a descoberta mais recente é o tecido adiposo, sendo responsáveis, principalmente, pela renovação celular. Nos últimos anos muito se tem pesquisado sobre células-tronco e a literatura aponta as células-tronco mesenquimais (CTMs) como as mais promissoras.

A medula óssea é uma das principais fontes de isolamento de células-tronco mesenquimais, no entanto, tem menor potencial de diferenciação e tempo de vida máximo que diminui com o passar da idade. O cordão umbilical é uma grande fonte de células-tronco, no entanto, pode ser obtido apenas em um único momento da vida e possui características semelhantes às células da medula-óssea. A epiderme também contém uma subpopulação de células basais que exibem propriedades esperadas de células tronco: ciclo celular lento, alto potencial de proliferação, localizada protetivamente, habilidade de manter e reparar o tecido em que reside e longo espectro de vida (BERTANHA M, et al., 2014).

A coleta de medula óssea é um método altamente invasivo e doloroso, que deve ser realizado sob anestesia geral ou bloqueio regional. A obtenção do cordão umbilical é uma alternativa mais segura, livre de risco e que não oferece dor para mãe ou para o neonato. O método mais utilizado de coleta de células faz uso da técnica da lipoaspiração úmida (BERTANHA M, et al., 2014). Outro método bastante comentado envolve a digestão enzimática de lipoaspiração para que haja a liberação da fração vascular estromal de células que envolvem as endoteliais e estromais e várias outras células brancas do sangue, com a utilização mais comum da colagenase como preparo enzimático (BOURIN P, et al., 2013).

O tecido adiposo subcutâneo corresponde a uma fonte de obtenção expressiva de células tronco mesenquimais (CTMs) devido à grande quantidade destas no mesmo. Esse tecido possui alta variedade celular, sendo formado por adipócitos maduros em sua maior parte, pré-adipócitos, fibroblastos, células de músculo liso da fração vascular, células endoteliais, monócitos, macrófagos e linfócitos (CASPAR-BAUGUIL, et al., 2005). Dessa forma, apresenta um alto potencial de uso na terapia celular, uma vez que apresenta alta capacidade de autorrenovação e grande habilidade de se diferenciar em variados tipos celulares.

Outro ponto importante é a facilidade de obtenção do tecido adiposo por um procedimento cirúrgico simples, as clínicas de cirurgia plástica lidam diariamente com a retirada de tecido adiposo por questões estéticas e a maior parte deste material de alto valor biológico é descartado. Com a evidência do sucesso do uso das CTMs derivadas do tecido adiposo na terapia celular, os produtos destas cirurgias têm sido cada vez mais aproveitados para a reconstrução de tecidos - sendo útil para o tratamento de enfermidades nas quais 
há perda ou disfunção tecidual - e biotecnologia. Deste modo, o tecido adiposo mostra-se bastante eficiente por ser uma fonte abundante de CTMs, de fácil acesso para coleta e com um desconforto reduzido para o paciente (GOMES RS, 2011).

É fundamental ter conhecimento pleno das possíveis vias de inoculação das células tronco e seus respectivos mecanismos reguladores da migração para a microcirculação do tecido-alvo, podendo ter uma melhor compreensão das possibilidades terapêuticas e melhora do desempenho do uso de células tronco. A via de inoculação das células-tronco mesenquimais (MSC) vai exercer influência no alcance dos órgãos alvos. Esse tipo de administração pode ser realizado através das vias endovenosa, intraperitoneal, intra-arterial ou intracardíaca. Apesar da via endovenosa ser a menos invasiva, as vias intracardíaca e intra-arterial têm demonstrado melhores resultados de integração com os tecidos-alvo (GOMES RS, 2011).

\section{Aplicação}

Nos últimos anos, ocorreram avanços significativos na Cirurgia Plástica, o que despertou interesse para o tema e a participação nas pesquisas de células-tronco a partir do momento que o tecido adiposo e a pele tornaram-se fontes de obtenção e diferenciação dessas células. A partir disso, abriram-se novas perspectivas de tratamento para deformidades congênitas e adquiridas, com finalidade reparadora ou estética, dando ênfase nas células do tecido adiposo (ADSC) e de pele. Após a obtenção de resultados satisfatórios no campo da cirurgia reconstrutiva, a técnica foi introduzida no campo da cirurgia plástica, visando restaurar forma e função, com procedimentos altamente tecnológicos e que muitas vezes limitam outras especialidades (SALIBIAN AA, et al., 2013).

Com os avanços recentes em imagens médicas, microcirurgia, alotransplante de tecido composto, nanotecnologia, biologia celular e biomateriais, as opções de tratamento para os pacientes estão mais amplas do que nunca. Existem boas perspectivas para ampliar gradualmente o portfólio de terapias baseadas no uso de células-tronco e sua utilização no tratamento de feridas e fístulas crônicas, reconstruções mamárias, tratamento de cicatrizes, bem como na cura de ossos, tendões e nervos periféricos. No entanto, apesar das aplicações bem-sucedidas, ainda existem muitos problemas potenciais associados aos riscos biológicos, que devem ser superados. Outras investigações devem ser focadas principalmente na segurança biológica e oncológica de aplicações de MSCs. (AGRAWAL NA, et al., 2019).

Os ADSCs têm a capacidade de produzir diversos tipos de tecidos sendo uma fonte de células ideais para a aplicação clínica, gerando um interesse por parte da indústria e a engenharia de tecidos para oferecer reconstrução semelhante, sem morbidade do local doador ou imunossupressão, combinando terapia de células-tronco com um material 3D feitos de materiais biológicos ou sintéticos e fatores de crescimento. Um progresso significativo foi feito recentemente na aplicação de células-tronco mesenquimais na construção de tecidos moles e cicatrização de feridas cutâneas com base na capacidade inerente dessas células para aumentar a angiogênese, minimizar a inflamação, auto-renovar e diferenciar-se em tipos de células especializados sob condições fisiológicas específicas (NADERI N, et al., 2017).

Os desafios futuros destas tecnologias envolvem suas formas de aplicação e as etapas necessárias para preencher a lacuna de transição que existe atualmente. Em particular, o mecanismo de ação das ADSCs, suas interações com os microambientes da matriz extracelular e o destino de longo prazo requerem maior esclarecimento e estudo (NADERI N, et al., 2017).

\section{Aplicabilidade Cirúrgica}

A capacidade das células-tronco de renovação, secreção de fatores tróficos e diferenciação em distintos tipos celulares permitiu o desenvolvimento de terapias mais flexíveis (BANYARD DA, et al., 2015). O uso de células tronco somáticas apresenta uma saída promissora para a regeneração de tecidos cruciais, como músculo cardíaco ou o tecido nervoso central (NADERI N, et al., 2017). Entretanto, maiores estudos ainda são necessários para melhor definir a fonte de células multipotentes, otimizando o isolamento dessas células em complacência com os padrões regulatórios e melhor entendimento do comportamento destas no local de transplante (BANYARD DA, et al., 2015).

As principais células utilizadas no tratamento com células-tronco no contexto na cirurgia plástica são as células-tronco do tecido adiposo (ATSC), que podem ser empregadas em inúmeras cirurgias como rejuvenescimento facial, lipodistrofia facial, rejuvenescimento da mão, atrofia dos membros inferiores, 
cirurgias reconstrutivas e estéticas, revisão de cicatriz e tratamento de danos teciduais por radioterapia (AGRAWAL et al., 2019). O tecido adiposo é o único no corpo humano que tem a habilidade de regular sua própria irrigação sanguínea, além de sua alta plasticidade (ANDRADE MGL e TUFANIN A, 2013). Essas células têm vários efeitos positivos quanto à reparação de feridas, imunomodulação e anti-apoptose (ZHANG S, et al., 2014). No entanto, diversos fatores afetam as propriedades das células-tronco adiposas, como a localização das reservas, comorbidades médicas do paciente e o método de coleta do tecido (LEE HC, et al., 2012).

A utilização de ATSC para regenerar tecidos moles mostrou-se bastante promissora nos últimos anos, dando suporte para a revascularização e regeneração por meio da secreção de fatores de crescimento angiogênicos (BANYARD DA, et al., 2015). As células-tronco do tecido adiposo tem alto potencial proliferativo e diferenciativo e podem ser aplicadas em processos cicatriciais. Essas células foram testadas em algumas ocasiões para a reparação de feridas, sendo avaliadas dentro dos parâmetros coloração, aspecto das bordas, presença de crostas, tecido de granulação, sinais de dor, sangramento e secreções. Os objetivos para o tratamento de feridas são o fechamento rápido, restauração de função e satisfação estética (GARCIA CSC, et al., 2016).

Estudos mostraram que as ATSC têm grande capacidade de se diferenciar em queratinócitos e epiderme estratificada (GARCIA CSC, et al., 2016). Em face à aplicação dessas células, ocorre o aumento significativo da densidade dos vasos, colágeno e da secreção de fatores de crescimento de endotélio vascular (VEGF) e fator de crescimento transformante beta 3 (TGFb3), os quais mediam o aumento da angiogênese, a cicatrização de feridas e, em consequência, o aumento da sobrevivência e espessura total do enxerto de pele, mostrando-se um tratamento promissor para uso em cirurgias de reconstrução e reparação. Acrescenta-se que essas células podem ser úteis para a terapia celular pois oferecem uma cobertura epidérmica em casos de ampla perda de pele (KOZLIK M e WÓJCICKI P, 2014).

Acredita-se que células-tronco se integram ao local de reparação de pele, acelerando o processo ao se diferenciar nas células necessárias, desencadeando o mesmo processo em células adjacentes (NADERI N, et al., 2017). Estudos mostram, ainda, que o transplante de ATSC pode melhorar a qualidade da pele e aumentar o volume, o que, provavelmente, deve-se ao efeito das células tronco mesenquimais (ZHANG S, et al., 2014). O uso de células tronco para o rejuvenescimento da pele comprometida por fótons também teve resultados positivos e melhora geral na textura da pele e nas rugas (SALIBIAN AA, et al., 2013).

Ademais, células-tronco adiposas vem se mostrando propícias para procedimentos por secretarem citocinas fundamentais no processo de cura de feridas, além de ajudar no recrutamento de macrófagos, aumentar a granulação do tecido e a vascularização. Essas células já foram utilizadas para tratar diversos tipos de feridas, como lesões severas e irreversíveis induzidas por atrofia, fibrose, ulceração e retração. 0 uso de células tronco adiposas são uma alternativa menos invasiva para lesões cutâneas crônicas. Células tronco adiposas também são recomendadas para tratar feridas patológicas, no contexto de cicatrização que não agrada esteticamente o paciente, sendo uma solução para casos de cicatrização excessiva (SALIBIAN AA, et al. 2013).

Os resultados dos processos de cicatrização dependem do tamanho, profundidade e tipo de defeito, mas mostram-se animadores, dado que estudos mostram que a terapia com células tronco conseguiu promover cicatrizes melhores em questão de estética (KIM YJ e JEONG JH, 2014). Em determinados casos de abdominoplastia, foi empregada a técnica de retirada de gordura infra umbilical para a injeção de células na ferida operatória, apresentando grande sucesso (ANDRADE MGL e TUFANIN A, 2013).

Cirurgias mamárias também têm sido incluídas na utilização de células-tronco adiposas e muitos estudos vêm mostrando resultados positivos. Para redução de mama pouca diferença foi evidenciada, no entanto, para a reconstrução desse órgão, foi atestado uma melhoria no volume do seio, apesar da significância das células não terem sido demonstrados. A utilização de lipotransferência assistida por células gera grandes melhoras nos resultados das cirurgias, como melhoria na circunferência da mama em cirurgias cosméticas (SALIBIAN AA, et al., 2013). A suplementação de enxertos adiposos com células-tronco mesenquimais podem melhorar a sobrevivência a longo termo e retenção da peça e a taxa de complicação após esse enxerto foi menor do que reportado após cirurgias e procedimentos feitos com implantes (BOHÁČ M, et al., 2016). 
Vários estudos sugerem que células-tronco adiposas têm o potencial de se diferenciar em células endoteliais e secretar fatores paracrinos que estimulam o endotélio capilar. Por essa propriedade angiogênica, essas células têm alto potencial em situações isquêmicas como infarto do miocárdio ou doenças periféricas e cerebrais (NADERI N, et al., 2017; KIM YJ e JEONG JH, 2014). Células tronco da medula óssea também se mostraram muito promissoras em caso de isquemia límbica, apesar de ter alguns efeitos adversos como reduzida angiogênese (SALIBIAN AA, et al., 2013).

As células-tronco também já foram aplicadas na reconstrução óssea. Pesquisas mostram que as ATSC têm a capacidade de ossificar defeitos sem o uso de fator de crescimento exógeno, provendo um método simples de reconstrução óssea autóloga (SALIBIAN AA, et al., 2013). O tecido ósseo tem grande capacidade regenerativa, no entanto, em casos de grande perda tecidual, o uso de MSC é bastante indicado na aplicação de técnicas como enxertos ósseos e produtos de engenharia tecidual. Vários estudos mostram que MSCs têm maior habilidade regenerativa do que o tecido ósseo sozinho. Estudos com células de medula óssea mostraram regeneração acelerada sem efeitos adversos (BOHÁČ M, et al., 2016).

Já as reparações de cartilagens são desafiadoras para a prática médica, dada a baixa capacidade regenerativa do tecido. Em face do grande número de pessoas que sofrem com artrite, muitas pesquisas têm sido feitas em torno do uso dessas células para a regeneração da cartilagem articular, dado que as outras opções terapêuticas e cirúrgicas são pouco efetivas (NADERI N, et al., 2017). Assim, a utilização de célulastronco da medula óssea vem se mostrado promissoras para reparar cartilagem articular com defeitos por transplante ou injeções intra-articulares (SALIBIAN AA, et al., 2013).

\section{Riscos e controvérsias}

Nos curativos de 2a geração, as células tronco tecido específicas são incorporadas a produtos já disponíveis no mercado, e são elaborados para reproduzir a estrutura e a função da pele. Há alguns produtos disponíveis comercialmente, como por exemplo o Apligraf e Dermagraft, que certamente são produtos com resultados extremamente satisfatórios, porém dentre os seus fatores limitantes encontram-se o tempo necessário para cultura de células autólogas, os riscos biológicos de material homólogo e os custos relacionados ao preparo destes materiais (NUNES HC, 2014).

Além disso, as células tronco adultas obtidas da polpa de dente e do músculo orbicular do lábio associadas aos scaffolds de colágeno, mostraram ser promissoras para reabilitação das fissuras lábio palatinas. Alguns grupos demonstraram o fechamento de defeitos críticos em ratos e camundongos utilizando células tronco provenientes de aspirado de medula óssea utilizando diferentes materiais biológicos sintéticos e também obtiveram sucesso. No entanto, eles utilizaram animais imunossuprimidos e, para a obtenção de células tronco adultas (CTA) provenientes de aspirado de medula necessita-se da realização de um procedimento invasivo (BUENO DF, 2007).

Outrossim, o telejornalismo brasileiro apresenta forte polarização em torno do estudo das células tronco, proporcionando ênfase para os que defendem o tema, como cientistas e pesquisadores, em contrapartida dos que são contra, principalmente religiosos. Nessa pesquisa, foram incluídos jornais entre os anos de 2005 e 2008, os mesmos omitindo alguns resultados de pesquisas com células tronco embrionárias, em que os riscos induzidos à formação de tumores não foram apresentados, demonstrando o forte poder de manipulação da mídia (ALMEIDA C, et al., 2013).

\section{CONSIDERAÇÕES FINAIS}

A relevância do uso de células-tronco no ramo da cirurgia plástica e da sua aplicação na restauração estética e funcional dos tecidos é notória. A medicina regenerativa com células-tronco progrediu significativamente na última década e desenvolvem-se novas perspectivas para correção de deformidades adquiridas e congênitas, alterações cicatriciais, queimaduras e estrias, associadas à necessidade constante de produzir tecido adicional ou moldar o tecido existente, com finalidade reparadora ou estética. Os avanços clínicos sugerem um futuro promissor para a abertura de uma nova estratégia terapêutica celular em cirurgia plástica e, dessa forma, torna-se imprescindível entender e correlacionar as células-tronco do tecido adiposo com o processo de cicatrização. 


\section{REFERÊNCIAS}

1. AGRAWAL NA, et al. Stem Cells and Plastic Surgery. Seminars in Plastic Surgery, 2019. 33(3): 162-166.

2. ALMEIDA C, et al. Controvérsia científica no telejornalismo brasileiro: um estudo sobre a cobertura das células-tronco no Jornal Nacional. História, Ciências, Saúde - Manguinhos, 2013. 20(1): 1203-1223.

3. ANDRADE MGL, et al. Células-tronco derivadas do tecido adiposo e sua utilização na cicatrização de lesões cutâneas: revisão bibliográfica. 2013.

4. BANYARD DA, et al. Implications for human adipose-derived stem cells in plastic surgery. Journal of Cellular and Molecular Medicine, 2015. 19(1): 21-30.

5. BERTANHA M, et al. Tissue-engineered blood vessel substitute by reconstruction of endothelium using mesenchymal stem cells induced by platelet growth factors. Journal of Vascular Surgery, 2014. 59(6): 1677-1685.

6. BOHÁČ M, et al. Stem cell regenerative potential for plastic and reconstructive surgery. Cell and Tissue Banking, 2016. 17(4): 735-744.

7. BOURIN P, et al. Stromal cells from the adipose tissue-derived stromal vascular fraction and culture expanded adipose tissue-derived stromal/stem cells: a joint statement of the International Federation for Adipose Therapeutics and Science (IFATS) and the International Society for Cellular Therapy (ISCT). Cytotherapy, 2013. 15(6): 641-648.

8. BUENO DF. Uso de Células Tronco Adultas para Estudo da Etiopatogenia das Fissuras Lábio Palatinas e Bioengenharia de Tecidos. Dissertação (Doutorado em Genética e Biologia evolutiva), Universidade de São Paulo, 2007.

9. CASPAR-BAUGUIL $S$, et al. Adipose tissues as an ancestral immune organ: Site-specific change in obesity. FEBS Letters, 2005.

10. EUN SC. Stem cell and research in plastic surgery. Journal of Korean Medical Science. 2014. 29(3): $167-S 169$.

11. GAGE FH. Mammalian Neural Stem Cells. Science, 2000. 287(5457): 1433-1438.

12. GARCIA CSC, et al. Adipose tissue-derived stem cell autologous grafts: a new approach to application in the treatment of burn victims and reconstructive plastic surgery. Revista Brasileira de Cirurgia Plástica (RBCP) - Brazilian Journal of Plastic Surgery, 2016. 31(3): 417-423.

13. GOMES RS. Perspectivas do uso de células-tronco em Cirurgia Plástica. Revista Brasileira de Cirurgia Plástica, 2011. 26(1): 151-159.

14. KIM YJ, JEONG JH. Clinical application of adipose stem cells in plastic surgery. Journal of Korean Medical Science, 2014. 29(4): 462-467.

15. KOŹLIK M, WÓJCICKI P. The use of stem cells in plastic and reconstructive surgery. Advances in Clinical and Experimental Medicine, 2014. 23(6): 1011-1017.

16. LEE HC, et al. Safety and effect of adipose tissue-derived stem cell implantation in patients with critical limb ischemia: a pilot study. Official journal of the Japanese Circulation Society, 2012. 76(7): 1750-1760.

17. LOEFFLER M, et al. Clonality and Life Cycles of Intestinal Crypts Explained by a State Dependent Stochastic Model of Epithelial Stem Cell Organization. Journal of Theoretical Biology, 1997.

18. MORRISSON SJ, et al. Regulatory Mechanisms in Stem Cell Biology. Cell Press, 1997. 88: 287-298.

19. NADERI N, et al. The regenerative role of adipose-derived stem cells (ADSC) in plastic and reconstructive surgery. International Wound Journal, 2017. 14(1): 112-124.

20. NUNES HC. Estudo comparativo de três diferentes scaffolds para crescimento de célula tronco mesenquimal, fibroblastos e queratinócitos. Dissertação (Mestrado em Pesquisa e desenvolvimento) - Biotecnologia Médica. Universidade Estadual Paulista (UNESP), Botucatu, 2014.

21. ROBEY PG. Stem cells near the century mark. The Journal Of Clinical Investigation, 2000.

22. SALIBIAN AA, et al. Stem cells in plastic surgery: A review of current clinical and translational applications. Archives of Plastic Surgery, 2013. 40(6): 666-675.

23. TREMOLADA C, et al. Adipocyte Transplantation and Stem Cells: Plastic Surgery Meets Regenerative Medicine. Cell Transplantation, 2010.

24. ZHANG S, et al. Anti-aging effect of adipose-derived stem cells in a mouse model of skin aging induced by D-galactose. PLoS ONE, 2014. 9(5): 1-7. 